\title{
Epidemiological Patterns of Central Nervous System Neoplasms in Brazilian Vulnerable Children
}

\author{
Andre Akira Ramos Takahashi, \\ Livia Akemi Ramos Takahashi, \\ Sandra Di Felice Boratto, \\ Leonardo Alfano de Lima, \\ Laercio da Silva Paiva, \\ Stefanie de Sousa Antunes Alcantara, \\ Luiz Vinicius de Alcantara Sousa,
} Faculdade de Medicina do ABC; Epidemiology Department

\begin{abstract}
Introduction: Central nervous system (CNS) neoplasms are the most common solid tumors within the pediatric population, being an important cause of death and functional losses in this age group. Although studies show that there is good evolution and adaptation of pediatric survivors in adulthood, the interaction of these individuals with social inclusion factors still worries the medical environment. Objective: To analyze the temporal trend of mortality, hospitalization and social vulnerability of children with CNS Neoplasia and correlate with social indicators. Methods: An ecological study carried out in November 2018, through the analysis of secondary data on mortality, hospital admission, social vulnerability index and social indicators of Brazil, collected in DATASUS, and the Atlas of Social Vulnerability available at the Institute of Economic Research in the period from 2010 to 2015. Results: The improvement of social variables in all Brazilian regions; There was an increase in hospitalizations for Nervous System neoplasms for the 5 to 9 -year-old male in the Northeast region; To the North, in the age group 0 to 4 years the hospitalization rates were positively correlated with the IVS, negatively with the HDI and positively with the Gini index; It was possible to identify a negative correlation between the IVS and the total number of hospitalizations for the Northeast in the female sex; Regarding mortality, there was a positive correlation between total mortality and IVS in the Midwest for the male population. Conclusion: It was concluded that there was a correlation between the various social indexes (HDI, IVS and Gini index) and the
\end{abstract}


incidence and mortality due to Central Nervous System neoplasms in the pediatric population.

Keywords: Neoplasm, Central Nervous System, Socioeconomic factors, Pediatrics

\section{Introduction}

Central nervous system (CNS) neoplasms are the most common solid tumors within the pediatric population, being an important cause of death and functional losses in this age group (Ostrom, 2014) (Mora, 2018). Low-grade gliomas are more commonly found in children, about 50\%, with astrocytoma being the most common neoplastic type (Sturm, 2017) (Louis, 2007).

Although studies show that there is good evolution and adaptation of pediatric survivors in adulthood (Zeltzer, 2009) (Michel, 2010), the interaction of these individuals with social inclusion factors still worries the medical environment (Strauser, 2018). Work, for example, is an important source of income, independence, and social interaction in adult life, yet the sequelae left by CNS neoplasms during childhood impair up to eight times the ability to obtain work compared to healthy survivors (Kirchoff, 2010) (Kirchhoff, 2010).

Socioeconomic status and patterns of social vulnerability have already been related to the increase in mortality due to several diseases and even the increase in the incidence of some neoplasms in children (Starfield, 2002) (Sommer, 2015). This is due to several behavioral and environmental factors that when associated may interfere with quality of life and predisposition to numerous morbidities (Kehm, 2017). Despite this importance, knowledge is still considered little, especially when it comes to the scientific evidence about possible associations with socioeconomic factors, and the information found in the international databases is often contradictory and does not reach a consensus, for varying positive associations between these variables (Pan, 2010) (Kamihara, 2017) (Alston, 2007) (Keegan, 2013).

Despite vacancies, studies in developed countries seek to associate socioeconomic and vulnerability variables with the incidence of cancer in several segments of society, with expressive results regarding the higher incidence and mortality of different types of cancer in the socioeconomic disparity classes and of greater vulnerability (Baquet, 1997). Nevertheless, studies in lower income countries, in which socioeconomic dichotomies are even more evident, still lack in the literature, which impairs the understanding of this relevant topic.

Thus, it is important to research on possible associations between socioeconomic variables and CNS neoplasia in children. For this, the choice of a locality in which different regions of each other are located, as to their 
culture and their socioeconomic characteristics is of exponential impact so that a wider comparison of these variables is possible. It is in this sense that Brazil was considered for the accomplishment of the present work, since it is a country of deep and well-known social, cultural and economic inequalities between its regions, which allows a complex analysis of the factors of social vulnerability and how these factors may be influencing the epidemiological pattern of Central Nervous System neoplasms in children.

In this context, this study aims to analyze the temporal trend of mortality, hospitalization and social vulnerability of children with Central Nervous System Neoplasia and correlate with social indicators.

\section{Methods}

An ecological study carried out in November 2018, through the analysis of secondary data on mortality, hospital admission, social vulnerability index (IVS) and social indicators of Brazil, collected in DATASUS, and the Atlas of Social Vulnerability available at the Institute of Economic Research (IPEA) in the period from 2010 to 2015.

Because it is a research of secondary data, where access is free and unrestricted, there was no need for the appreciation of the Research Ethics Committee for human beings.

Brazil is considered an extensive, medium-income country, divided into five administrative regions: The North, the Northeast, the Southeast, the South, and the Midwest. These regions present population differences depending on each area.

The Department of Informatics of the Unified Health System (DATASUS) is a database with all the health information of Brazil, with access is free through the website: www.datasus.gov.br (Ministério da Saúde, 2019).

The Gini index was collected in the IPEA system and measured the income inequality per capita. This index ranges from 0 to 1 , the value close to 1 represents income inequality and the values close to zero represent the opposite (Brasil A, 2013). In addition, the HDI, available on the IPEA platform, compares indicators in the areas of wealth, literacy, education, life expectancy, birth rate, and others, in order to assess the well-being of a population, especially children. It ranges from zero to one and is released by the United Nations Development Program (UNDP) in its annual report (Brasil A, 2013).

The IVS seeks to assess the issue of social vulnerability and exclusion in Brazil, taking into account other aspects of poverty, not only the lack of financial resources, and is built on the Atlas of Human Development (ADH) in Brazil. This IVS brings 16 indicators structured in three dimensions: I) IVS urban infrastructure; II) IVS human capital and III) IVS income and work. The 
IVS index ranges from 0 to 1 , the closer the result to 1 , the greater the social vulnerability of a locality. For localities that present IVS between 0 and 0,200 it is considered very low social vulnerability, between 0,201 to 0,300 indicate low vulnerability, between 0.301 to 0.400 are average social vulnerability, between 0,401 and 0,500 are considered high vulnerability and between 0,501 to 1 the locality very high social vulnerability (Atlas da Vulnerabilidade Social nas Regiões Metropolitanas Brasileiras, 2015).

The study was composed of all deaths recorded in the Mortality Information System (SIM) and all hospital admissions from the Hospital Information System of the Unified Health System (SIH / SUS) by Malignant Neoplasia of the Central Nervous System (CNS) in children between January 1, 2010 and December 31, 2015, in all Brazilian residents.

Data on death and hospital admission for malignant neoplasm of the CNS were collected using the International Classification of Diseases in its 10th revision (CID-10) with codes C70, C71 and C72 for the total population and stratified by regions (North, Northeast, Southeast, South and Midwest), age groups (0-4 years, 5-9 years and 10-14 years), sex (male and female) and calendar years $(2010,2011,2012,2013,2014$ and 2015) according to the availability of DATASUS data. However, the census of 2010 and the intercensorial projections (2011 to 2015) of the Brazilian Institute of Geography and Statistics (IBGE) were also used to collect data on the total population, which is also available in the DATASUS system.

Mortality rates (number of deaths by the total population at risk) and hospital admission in children (hospital admissions by the total population at risk) per 100,000 inhabitants, stratified by age groups, regions, sex and civil years, were calculated. Subsequently, mortality rates and hospital admission were standardized by age by direct method according to the World Health Organization (WHO) (Ahmad, 2001).

\section{Statistical analysis}

Pearson's correlation was used to compare the rates of hospitalization and mortality in children due to social vulnerability and social indicators (HDI and Gini index) according to age, gender and regions, in addition, social vulnerability indexes and social indicators regions of Brazil.

The trend of the mortality rate and hospitalization for malignant CNS cancer in children in the regions of Brazil by sex stratified in age groups was evaluated using Linear Regression. The values of $\beta$ (angular coefficient), $p$ (probability) and $\mathrm{r}^{2}$ (predictive capacity of the model) were used.

The confidence level adopted for all analyzes was $95 \%$ and the statistical program used was Data Analysis and Statistical Software for Professionals (Stata) version 11.0®. 


\section{Results}

As for the social vulnerability index of the North, there was a reduction of -0.02 (CI: $\left.-0.041 ;-0.002, p=0.038, \mathrm{r}^{2}=0.70\right) \mathrm{r} 2=0.66, \mathrm{p}=0.05$ ) for the variable Income and Labor, an increase of 0.009 (CI: $0.005 ; 0.001, \mathrm{r}^{2}=0.89$, $\mathrm{p}=0.005)$ of the HDI, a reduction of $-0.02\left(\mathrm{CI}:-0.04 ;-0.001, \mathrm{r}^{2}=0.69, \mathrm{p}=\right.$ $0.041)$ of the Gini index and a reduction of $-0.002\left(\mathrm{CI}=-0.05 ;-0.003 ; \mathrm{r}^{2}=\right.$ $0.72, p=0.032$ ) for the total IVS. In the Northeast there was an increase in HDI by 0.008 (CI: $0.004,0.012, \mathrm{r}^{2}=0.87, \mathrm{p}=0.007$ ) and a reduction of -0.02 (CI: $-0.04 ;-0.001, \mathrm{r}^{2}=0.68, \mathrm{p}=0.042$ ) in the Gini index. In the Southeast, the reduction to the Human Capital variable of the IVS was -0.001 (CI: -0.02; $\left.0.003, \mathrm{r}^{2}=0.77, \mathrm{p}=0.021\right)$ and there was an increase of 0.005 (CI: 0.003, $\left.0.008, \mathrm{r}^{2}=0.87, \mathrm{p}=0.007\right)$. (Table 1)

Table 1. Linear Regression of Social Vulnerability Index.

\begin{tabular}{|c|c|c|c|c|c|c|c|c|c|c|c|c|c|c|c|}
\hline \multirow[b]{2}{*}{ Variables } & \multicolumn{3}{|c|}{ IVs-North } & \multicolumn{3}{|c|}{ IVS - Northeast } & \multicolumn{3}{|c|}{ IVs-Southeast } & \multicolumn{3}{|c|}{ IVs-South } & \multicolumn{3}{|c|}{ IVS-Mildwest } \\
\hline & B (CI95\%) & $\mathrm{p}^{*}$ & $r^{2}$ & $\begin{array}{c}\text { B } \\
(\mathrm{CI} 95 \%)\end{array}$ & $\mathrm{p}^{*}$ & $\mathrm{r}^{2}$ & $\begin{array}{c}\mathrm{B} \\
(\mathrm{CI} 95 \\
\%) \\
\end{array}$ & $\mathrm{p}^{*}$ & $r^{2}$ & $\begin{array}{c}\mathrm{B} \\
(\mathrm{CI} 95 \%)\end{array}$ & $\mathrm{p}^{*}$ & $r^{2}$ & $\begin{array}{c}\text { B } \\
(\mathrm{CI} 95 \%)\end{array}$ & $\mathrm{p}^{*}$ & $r^{2}$ \\
\hline $\begin{array}{c}\text { Urban } \\
\text { infrastruc } \\
\text { ture }\end{array}$ & $\begin{array}{c}-0.03(-0.06 ;- \\
0.005)\end{array}$ & 0.032 & $\begin{array}{c}0.72 \\
23\end{array}$ & $\begin{array}{c}0.02(- \\
0.03 ; \\
0.002)\end{array}$ & $\begin{array}{c}0.07 \\
5\end{array}$ & $\begin{array}{l}0 . \\
58 \\
80\end{array}$ & $\begin{array}{c}-0.01 \\
4(- \\
0.03 ; \\
0.004)\end{array}$ & $\begin{array}{c}0.10 \\
1\end{array}$ & $\begin{array}{c}0.52 \\
94\end{array}$ & $\begin{array}{c}0.0003(- \\
0.016 \\
0.017)\end{array}$ & $\begin{array}{c}0.96 \\
1\end{array}$ & $\begin{array}{c}0.00 \\
07\end{array}$ & $\begin{array}{c}-0.01(- \\
0.02 ; \\
0.002)\end{array}$ & 0.095 & $\begin{array}{c}0.54 \\
23\end{array}$ \\
\hline $\begin{array}{l}\text { Human } \\
\text { Capital }\end{array}$ & $\begin{array}{c}-0.022(- \\
0.041 ;-0.002)\end{array}$ & 0.038 & $\begin{array}{c}0.70 \\
12\end{array}$ & $\begin{array}{c}0.015(- \\
0.03 ; \\
0.002)\end{array}$ & $\begin{array}{c}0.06 \\
8\end{array}$ & $\begin{array}{l}0 . \\
60 \\
66\end{array}$ & $\begin{array}{c}-0.01 \\
(- \\
0.02 ;- \\
0.003)\end{array}$ & $\begin{array}{c}0.02 \\
1\end{array}$ & $\begin{array}{c}0.77 \\
44\end{array}$ & $\begin{array}{c}0.015(- \\
0.02 ;- \\
0.009)\end{array}$ & $\begin{array}{c}0.00 \\
2\end{array}$ & $\begin{array}{c}0.92 \\
75\end{array}$ & $\begin{array}{c}0.012(- \\
0.024 ; \\
0.0006)\end{array}$ & 0.057 & $\begin{array}{c}0.63 \\
66\end{array}$ \\
\hline $\begin{array}{l}\text { Income } \\
\text { and } \\
\text { Labor }\end{array}$ & $\begin{array}{c}-0.02(-0.04 \\
0.00)\end{array}$ & 0.050 & $\begin{array}{c}0.65 \\
72\end{array}$ & $\begin{array}{c}-0.02(- \\
0.04 ; \\
0.001)\end{array}$ & $\begin{array}{c}0.05 \\
7\end{array}$ & $\begin{array}{l}0 . \\
63 \\
76\end{array}$ & $\begin{array}{c}-0.00 \\
4(- \\
0.02 \\
0.02)\end{array}$ & $\begin{array}{c}0.59 \\
2\end{array}$ & $\begin{array}{c}0.07 \\
82\end{array}$ & $\begin{array}{c}0.009(- \\
0.02 ; \\
0.002)\end{array}$ & $\begin{array}{c}0.08 \\
4\end{array}$ & $\begin{array}{c}0.56 \\
79\end{array}$ & $\begin{array}{c}-0.01(- \\
0.03 ; \\
0.006)\end{array}$ & 0.154 & $\begin{array}{c}0.43 \\
52\end{array}$ \\
\hline HDI & $\begin{array}{c}0.009(0.005 \\
0.01)\end{array}$ & 0.005 & $\begin{array}{c}0.88 \\
69\end{array}$ & $\begin{array}{c}0.008 \\
(0.004 \\
0.012)\end{array}$ & $\begin{array}{c}0.00 \\
7\end{array}$ & $\begin{array}{l}0 . \\
86 \\
83\end{array}$ & $\begin{array}{c}0.005 \\
(0.003 \\
; \\
0.008)\end{array}$ & $\begin{array}{c}0.00 \\
7\end{array}$ & $\begin{array}{c}0.86 \\
82\end{array}$ & $\begin{array}{c}0.007 \\
(0.004 \\
0.01)\end{array}$ & $\begin{array}{c}0.00 \\
3\end{array}$ & $\begin{array}{c}0.91 \\
37\end{array}$ & $\begin{array}{c}0.006 \\
(0.002 ; \\
0.009)\end{array}$ & 0.010 & $\begin{array}{c}0.84 \\
00\end{array}$ \\
\hline $\begin{array}{l}\text { Gini } \\
\text { index }\end{array}$ & $\begin{array}{c}-0.02(-0.04 ;- \\
0.001)\end{array}$ & 0.041 & $\begin{array}{c}0.68 \\
69\end{array}$ & $\begin{array}{c}-0.02(- \\
0.04 ;- \\
0.001)\end{array}$ & $\begin{array}{c}0.04 \\
2\end{array}$ & $\begin{array}{l}0 . \\
68 \\
45\end{array}$ & $\begin{array}{c}-0.01 \\
(- \\
0.03 ; \\
0.006)\end{array}$ & $\begin{array}{c}0.15 \\
8\end{array}$ & $\begin{array}{c}0.42 \\
86\end{array}$ & $\begin{array}{c}0.01(- \\
0.03 ; \\
0.003)\end{array}$ & $\begin{array}{c}0.08 \\
7\end{array}$ & $\begin{array}{c}0.56 \\
06\end{array}$ & $\begin{array}{c}-0.02(- \\
0.03 ;- \\
0.004)\end{array}$ & 0.021 & $\begin{array}{c}0.77 \\
26\end{array}$ \\
\hline $\begin{array}{l}\text { Total } \\
\text { (IVS) }\end{array}$ & $\begin{array}{c}-0.02(-0.05 ;- \\
0.003)\end{array}$ & 0.032 & $\begin{array}{c}0.72 \\
2\end{array}$ & $\begin{array}{c}-0.02(- \\
0.03 ; \\
0.00)\end{array}$ & $\begin{array}{c}0.05 \\
8\end{array}$ & $\begin{array}{l}0 . \\
63 \\
33\end{array}$ & $\begin{array}{c}-0.01 \\
(- \\
0.02 \\
0.00)\end{array}$ & $\begin{array}{c}0.10 \\
1\end{array}$ & $\begin{array}{c}0.53 \\
07\end{array}$ & $\begin{array}{c}0.01(- \\
0.02 ; \\
0.003)\end{array}$ & $\begin{array}{c}0.10 \\
7\end{array}$ & $\begin{array}{c}0.51 \\
73\end{array}$ & $\begin{array}{l}-0.01(- \\
0.02 \\
0.00)\end{array}$ & 0.076 & $\begin{array}{c}0.58 \\
72\end{array}$ \\
\hline
\end{tabular}

* Linear regression

In the South, there was a reduction of the IVS Human Capital variable in -0.015 (CI: $\left.-0.02 ;-0.009, \mathrm{r}^{2}=0.93, \mathrm{p}=0.002\right)$ and an increase of 0.007 (CI: $\left.0.004,0.001, r^{2}=0.91, p=0.003\right)$ of the HDI. For the Central West, there was an increase of 0.006 (CI: $0.002,0.009, \mathrm{r}^{2}=0.84, \mathrm{p}=0.01$ ) of the HDI and a decrease of -0.02 in the Gini index (CI: $\left.-0.03,-0.004, \mathrm{r}^{2}=0.77, \mathrm{p}=0.021\right)$. (Table 1) 
Regarding the hospitalization rate for Central Nervous System neoplasms, there was an increase of 7.07 (CI: 1.95, 12.13, $\mathrm{r}^{2}=0.78, \mathrm{p}=0.018$ ) for the 5 to 9 -year-old male in the Northeast region. (Table 2)

In the North, for the 0-4 age group, there was a positive and statistically significant correlation between the IVS and the male $(r=0.82, p=0.048)$ and female $(r=0.85, p=0.03)$. For the other regions and age groups there was a correlation, however without statistical significance. (Table 3). However, it was possible to identify a negative correlation between the IVS and the total number of hospitalizations for the Northeast in the female sex $(r=-0.90, p=$ 0.015). (Table 5)

Table 2. Linear regression of the Male and Female rate of Hospitalization

\begin{tabular}{|c|c|c|c|c|c|c|}
\hline \multirow{2}{*}{ Regions } & \multicolumn{3}{|l|}{ Male } & \multicolumn{3}{|l|}{ Female } \\
\hline & B (IC95) & $\mathbf{p}^{*}$ & $\mathbf{r}^{2}$ & B (IC95) & $\mathbf{p}$ & $\mathbf{r}^{2}$ \\
\hline \multicolumn{7}{|c|}{ Age range 0 to 4 years } \\
\hline North & $-5.95(-19.99 ; 8.08)$ & 0.304 & 0.26 & $-3.83(-9.87 ; 2.20)$ & 0.153 & 0.43 \\
\hline Northeast & $1.68(-3.53 ; 6.89)$ & 0.421 & 0.17 & $-5.77(-25.20 ; 13.65)$ & 0.456 & 0.14 \\
\hline Southeast & $12.97(-7.79 ; 33.73)$ & 0.158 & 0.43 & $10.21(-10.08 ; 30.50)$ & 0.235 & 0.32 \\
\hline South & $-5.57(-49.74 ; 38.59)$ & 0.744 & 0.02 & $-19.24(-39.64 ; 1.16)$ & 0.059 & 0.63 \\
\hline Midwest & $19.12(-31.76 ; 70.02)$ & 0.356 & 0.21 & $27.03(-29.51 ; 83.59)$ & 0.255 & 0.3 \\
\hline \multicolumn{7}{|c|}{ Age range from 5 to 9 years } \\
\hline North & $3.77(-2.90 ; 10.44)$ & 0.192 & 0.38 & $0.19(-6.50 ; 6.89)$ & 0.94 & 0 \\
\hline Northeast & $7.04(1.95 ; 12.13)$ & 0.018 & 0.78 & $1.66(-2.51 ; 5.84)$ & 0.33 & 0.23 \\
\hline Southeast & $-0.69(-7.12 ; 5.72)$ & 0.778 & 0.02 & $1.06(-4.65 ; 6.79)$ & 0.633 & 0.06 \\
\hline South & $-9.17(-22.88 ; 4.54)$ & 0.137 & 0.46 & $-8.79(-20.50 ; 2.90)$ & 0.105 & 0.52 \\
\hline Midwest & $4.07(-2.53 ; 10.68)$ & 0.162 & 0.42 & $-4.33(-13.49 ; 4.81)$ & 0.259 & 0.3 \\
\hline \multicolumn{7}{|c|}{ Age group from 10 to 14 years } \\
\hline North & $-3.43(-11.69 ; 4.83)$ & 0.313 & 0.25 & $-2.29(-10.73 ; 6.15)$ & 0.493 & 0.12 \\
\hline Northeast & $2.47(-3.00 ; 7.96)$ & 0.278 & 0.28 & $2.05(-3.27 ; 7.38)$ & 0.344 & 0.22 \\
\hline Southeast & $-4.81(-11.83 ; 2.21)$ & 0.13 & 0.47 & $-5.71(-11.65 ; 0.21)$ & 0.055 & 0.64 \\
\hline South & $-0.67(-4.65 ; 3.30)$ & 0.662 & 0.05 & $-0.91(-10.01 ; 8.18)$ & 0.794 & 0.01 \\
\hline Midwest & $3.23(-1.91 ; 8.38)$ & 0.156 & 0.43 & $-0.25(-8.04 ; 7.54)$ & 0.932 & 0 \\
\hline
\end{tabular}

For the North region, the HDI was negatively correlated with the hospitalizations of the 0 to 4 age group for the female population $(r=-0.85, p$ $=0.03)$. In the Southeast this association was observed for the age range of 10 to 14 years for girls $(r=-0.90, p=0.014)$. (Table 6).

A positive correlation was observed between the Gini index and admissions for Central Nervous System neoplasms in the North for the 0 to 4year age group among boys $(r=0.83, p=0.043)$ and among girls $(r=0.84, p$ $=0.036)$. (Table 6). A positive correlation was also observed between the total Northeastern hospitalizations and the HDI among the female sex $(r=0.82, p$ 
$=0.045)$ and a negative correlation of these variables in the South among the girls $(\mathrm{r}=-0.82, \mathrm{p}=0.045)$, for the Gini index there was a negative correlation with the total hospitalizations of the Northeast for the female sex $(r=-0.84, p$ $=0.033$ ). (Table 7)

Table 3. Correlation between hospitalization rate and IVS in male and female.

\begin{tabular}{ccccc}
\hline Regions & \multicolumn{2}{c}{ Male } & \multicolumn{2}{c}{ Female } \\
\cline { 2 - 5 } & & $\mathbf{p}^{*}$ & $\mathbf{r}$ & $\mathbf{p}^{*}$ \\
\hline North & 0.82 & $\mathbf{0 . 0 4 8}$ & 0.85 & $\mathbf{0 . 0 3}$ \\
0 a 4 & -0.29 & 0.57 & -0.06 & 0.91 \\
5 a 9 & 0.17 & 0.75 & -0.001 & 0.998 \\
10 a 14 & & & & \\
Northeast & -0.42 & 0.41 & -0.14 & 0.80 \\
0 a 4 & -0.57 & 0.24 & -0.47 & 0.34 \\
5 a 9 & -0.22 & 0.68 & -0.16 & 0.77 \\
10 a 14 & & & & \\
Southeast & -0.23 & 0.66 & -0.45 & 0.37 \\
0 a 4 & 0.39 & 0.44 & -0.33 & 0.53 \\
5 a 9 & 0.39 & 0.45 & 0.65 & 0.17 \\
10 a 14 & & & & \\
South & -0.32 & 0.54 & 0.44 & 0.38 \\
0 a 4 & 0.10 & 0.85 & 0.44 & 0.38 \\
5 a 9 & 0.38 & 0.45 & 0.19 & 0.72 \\
10 a 14 & & & & \\
Midwest & -0.52 & 0.29 & -0.50 & 0.31 \\
0 a 4 & -0.08 & 0.88 & 0.51 & 0.30 \\
5 a 9 & -0.34 & 0.50 & 0.09 & 0.87 \\
10 a 14 & &
\end{tabular}

*Pearson Correlation

Table 4. Correlation of social indicators (HDI and Gini) with the Social vulnerability index of the regions

\begin{tabular}{ccccc}
\hline \multirow{2}{*}{ Regions } & \multicolumn{2}{c}{ HDI } & \multicolumn{3}{c}{ Gini } \\
\cline { 2 - 5 } & $\mathbf{r}$ & $\mathbf{p}^{*}$ & $\mathbf{r}$ & $\mathbf{p}^{*}$ \\
\hline North & -0.95 & $\mathbf{0 . 0 0 5}$ & 0.99 & $\mathbf{0 . 0 0 0}$ \\
Northeast & -0.94 & $\mathbf{0 . 0 0 5}$ & 0.96 & $\mathbf{0 . 0 0 3}$ \\
Southeast & -0.88 & $\mathbf{0 . 0 2 2}$ & 0.97 & $\mathbf{0 . 0 0 1}$ \\
South & -0.83 & $\mathbf{0 . 0 3 9}$ & 0.97 & $\mathbf{0 . 0 0 1}$ \\
Midwest & -0.95 & $\mathbf{0 . 0 0 4}$ & 0.97 & $\mathbf{0 . 0 0 2}$ \\
\hline & * Pearson Correlation. & &
\end{tabular}


Table 5. Correlation of the index of regional social vulnerability with hospitalization and mortality from cancer in the central nervous system.

\begin{tabular}{ccccccccc}
\hline \multirow{2}{*}{ Regions } & \multicolumn{2}{c}{$\begin{array}{c}\text { Hospitalization } \\
\text { and male IVS }\end{array}$} & \multicolumn{2}{c}{$\begin{array}{c}\text { Hospitalization and } \\
\text { female IVS }\end{array}$} & \multicolumn{2}{c}{$\begin{array}{c}\text { Mortality and } \\
\text { male IVS }\end{array}$} & \multicolumn{2}{c}{$\begin{array}{c}\text { Mortality and } \\
\text { female IVS }\end{array}$} \\
\cline { 2 - 9 } & $\mathbf{R}$ & $\mathbf{p}^{*}$ & $\mathbf{R}$ & $\mathbf{p}^{*}$ & $\mathbf{r}$ & $\mathbf{p}^{*}$ & $\mathbf{r}$ & $\mathbf{p}^{*}$ \\
\hline North & 0.25 & 0.63 & -0.51 & 0.303 & 0.1 & 0.856 & -0.11 & 0.831 \\
Northeast & - & 0.275 & -0.9 & $\mathbf{0 . 0 1 5}$ & -0.07 & 0.901 & -0.14 & 0.797 \\
Southeast & 0.69 & 0.13 & -0.34 & 0.513 & -0.41 & 0.421 & -0.21 & 0.684 \\
South & 0.02 & 0.963 & 0.56 & 0.25 & 0.34 & 0.516 & -0.36 & 0.483 \\
Midwest & - & 0.22 & -0.58 & 0.226 & 0.83 & $\mathbf{0 . 0 4 3}$ & -0.37 & 0.475 \\
\hline
\end{tabular}

* Pearson Correlation.

There was a positive and statistically significant correlation between IVS and Gini index for all regions and a negative association between IVS and HDI of all regions. (Table 4)

Regarding mortality, there was a positive correlation between total mortality and IVS in the Midwest for the male population $(r=0.83, p=0.043)$. (Table 5). For the same region and sex, a negative correlation was observed between total mortality and HDI $(\mathrm{r}=-0.92, \mathrm{p}=0.008)$ and a positive correlation between this mortality and the Gini index $(\mathrm{r}=0.85, \mathrm{p}=0.031)$. (Table 7).

Table 6. Correlation of the HDI and the Gini index of the regions with the hospitalization for cancer in the central nervous system.

\begin{tabular}{ccccc}
\hline \multirow{2}{*}{ HDI of the regions } & \multicolumn{2}{c}{ Male } & \multicolumn{2}{c}{ Female } \\
\cline { 2 - 5 } & $\mathbf{r}$ & $\mathbf{p}^{*}$ & $\mathbf{r}$ & $\mathrm{p}^{*}$ \\
\hline North & & & & \\
0 a 4 & -0.74 & 0.091 & -0.85 & $\mathbf{0 . 0 3}$ \\
5 a 9 & 0.36 & 0.479 & 0 & 0.996 \\
10 a 14 & -0.45 & 0.374 & -0.26 & 0.62 \\
Northeast & & & & \\
0 a 4 & 0.44 & 0.387 & -0.17 & 0.748 \\
5 a 9 & 0.8 & 0.054 & 0.43 & 0.395 \\
10 a 14 & 0.3 & 0.564 & 0.21 & 0.686 \\
Southeast & & & & \\
0 a 4 & 0.61 & 0.2 & 0.7 & 0.121 \\
5 a 9 & -0.23 & 0.661 & 0.13 & 0.8 \\
10 a 14 & -0.62 & 0.191 & -0.9 & $\mathbf{0 . 0 1 4}$ \\
On & & & & \\
0 a 4 & 0.02 & 0.975 & -0.72 & 0.105 \\
5 a 9 & -0.57 & 0.243 & -0.74 & 0.093 \\
10 a 14 & -0.39 & 0.445 & -0.18 & 0.737 \\
Midwest & & & & \\
0 a 4 & 0.61 & 0.196 & 0.61 & 0.195 \\
5 a 9 & 0.37 & 0.474 & -0.57 & 0.237 \\
10 a 14 & 0.43 & 0.392 & -0.16 & 0.757
\end{tabular}


Gini of the regions

North

0 a 4

5 a 9

0.83

0.043

0.84

0.036

10 a 14

$-0.27$

0.607

$-0.06$

0.917

Northeast

0 a 4

5 a 9

10 a 14

0.12

0.824

$-0.06$

0.912

\section{Southeast}

\section{0 a 4}

5 a 9

$-0.23$

0.661

0.04

0.946

$-0.58$

0.228

$-0.4$

0.429

$-0.22$

0.674

$-0.23$

0.662

10 a 14

$-0.24$

0.654

$-0.39$

0.444

0.27

0.611

$-0.22$

0.682

South

0 a 4

5 a 9

0.47

0.342

0.54

0.265

10 a 14

$-0.21$

0.691

0.5

0.317

0.12

0.814

0.38

0.456

Midwest

0.29

0.571

0.2

0.706

\section{0 a 4}

5 a 9

$-0.55$

0.259

$-0.61$

0.198

10 a 14

$-0.25$

0.636

0.57

0.237

$-0.48$

0.339

0.12

0.828

* Pearson correlation.

Table 7. Correlation of HDI and Gini with the index of Total Admissions and Mortality.

\begin{tabular}{|c|c|c|c|c|c|c|c|c|}
\hline \multirow{4}{*}{ Regions } & \multicolumn{8}{|c|}{ Index of Total Admissions } \\
\hline & \multicolumn{2}{|c|}{ HDI } & \multicolumn{2}{|c|}{ Gini } & \multicolumn{2}{|c|}{ HDI } & \multicolumn{2}{|c|}{ Gini } \\
\hline & $\mathrm{r}$ & $\mathrm{p}^{*}$ & $\mathrm{r}$ & $\mathrm{p}^{*}$ & $\mathrm{r}$ & $\mathrm{p}^{*}$ & $\mathrm{r}$ & $\mathrm{p}^{*}$ \\
\hline & \multicolumn{4}{|c|}{ Male } & \multicolumn{4}{|c|}{ Female } \\
\hline North & -0.3 & 0.555 & 0.26 & 0.608 & 0.37 & 0.459 & -0.48 & 0.325 \\
\hline Northeast & 0.77 & 0.07 & -0.56 & 0.244 & 0.82 & 0.045 & -0.84 & 0.033 \\
\hline Southeast & -0.33 & 0.512 & 0.72 & 0.104 & 0.1 & 0.84 & -0.21 & 0.681 \\
\hline South & -0.56 & 0.246 & 0.03 & 0.942 & -0.82 & 0.045 & 0.55 & 0.248 \\
\hline \multirow[t]{3}{*}{ Midwest } & 0.77 & 0.069 & -0.74 & 0.09 & 0.64 & 0.17 & -0.65 & 0.158 \\
\hline & \multicolumn{8}{|c|}{ Index of total Mortality } \\
\hline & & & & & & & & \\
\hline \multirow[t]{2}{*}{ Regions } & $\mathrm{r}$ & $\mathrm{p}^{*}$ & $\mathrm{r}$ & $\mathrm{p}^{*}$ & $\mathrm{r}$ & $\mathrm{p}^{*}$ & $\mathrm{r}$ & $\mathrm{p}^{*}$ \\
\hline & \multicolumn{4}{|c|}{ Male } & \multicolumn{4}{|c|}{ Female } \\
\hline North & 0 & 0.996 & 0.09 & 0.856 & 0.07 & 0.891 & -0.11 & 0.831 \\
\hline Northeast & -0.18 & 0.73 & 0.01 & 0.976 & 0.14 & 0.781 & -0.32 & 0.533 \\
\hline Southeast & 0.21 & 0.689 & -0.52 & 0.282 & 0.34 & 0.505 & -0.21 & 0.686 \\
\hline South & -0.2 & 0.702 & 0.47 & 0.343 & 0.45 & 0.369 & -0.16 & 0.753 \\
\hline Midwest & -0.92 & 0.008 & 0.85 & 0.031 & 0.12 & 0.815 & -0.19 & 0.705 \\
\hline
\end{tabular}




\section{Discussion}

In this study the main findings were:

1. The improvement of social variables in all Brazilian regions;

2. There was an increase in hospitalizations for Nervous System neoplasms for the 5 to 9 -year-old male in the Northeast region;

3 . To the North, in the age group 0 to 4 years the hospitalization rates were positively correlated with the IVS, negatively with the HDI and positively with the Gini index;

4. It was possible to identify a negative correlation between the IVS and the total number of hospitalizations for the Northeast in the female sex;

5. Regarding mortality, there was a positive correlation between total mortality and IVS in the Midwest for the male population

First, one can expect this improvement observed in social variables throughout the country. This is because Brazil is still in the socio-economic transition characterized by greater access to instruments that reflect a better quality of life for its population. An example of this is found in the best literacy rates found in a study that evaluates the functional literacy performance of the Brazilian school population, this marker is of exponential importance for better access to social inclusion means, such as work and higher income, and for understanding of their rights [18].

Regarding the hospitalization rates, the increase in the Northeast can be explained by the greater access of the population to the medical means of diagnosis. This greater access reflects the expansion of the Unified Health System, which, despite its resource constraints and high population demand, still constitutes a service of technical advances with some reference centers that provide diagnostic means for the population in general, following in certain principles of universality [19].

However, increasing hospitalization rates requires special and troubling analysis. It is an age group of neural and social formation of the child, corresponding to the pre-school period and the first years of basic education in which the individual receives numerous stimuli and is subject to important sequelae of an oncological treatment of his nervous system. Thus, a study proposed by Pulsifer et al in 2018 confirms this concern by showing a significant reduction in intelligence quotient and functional abilities in children who survived this treatment [20].

The finding that there was a higher incidence of Neoplasias in children aged 0 to 4 years, the worse their social indexes (IVS, HDI and Gini index) makes sense. This was observed in the North region, perhaps due to the greater socioeconomic disparity of this region compared to the rest of the country. An explanation for this association can be given not only by the child directly, but by maternal dietary factors. A study by Bunin shows that the maternal diet during gestation can influence the incidence of neoplasias of the nervous 
system, and the consumption of folate, vegetables and vitamins by the mothers were considered as protective factors for the development of cancer in the children in their first years of life [21]. This is directly related to social indicators, since it is intuitive to conclude that women in situations of social vulnerability and low income have less resources to plan their pregnancies in order to establish a balanced dietary intake.

However, it was observed that if we ignore the age group and analyze the hospitalizations of general forms in the Northeast, the IVS correlates negatively with the incidence. Although it seems contradictory, several studies support this finding, stating that the higher the socioeconomic status, the greater the chance of developing central nervous system cancer in children [22]. This would be explained by the greater exposure of pesticides and agrochemicals in this higher income population, which may be related to brain neoplastic processes [23-25]. This fact also explains why these findings are more evident in the total incidence and not in the age group, since these same studies affirm that the relation between the chemical products and neoplasias is "dose dependent", that is, it has a cumulative effect. Thus, the younger age groups, 0 to 4 years old, would not be so inserted in this risk since it is an age still not very affected by this cumulative effect and that would have a very natural feeding, due to the maternal breastfeeding up to 2 years in average. On the other hand, if we consider the pediatric population as a whole, the use of toxic products would be affecting the incidence of neoplasias more strongly due to the child's insertion into the family routine.

Finally, a positive association was established between IVS and total mortality due to central nervous system neoplasms. These findings corroborate studies stating that socioeconomic and racial disparities would be associated with more advanced stages of neoplasms and a longer travel time for treatment, that is, worse prognosis and treatment compliance [26]. In addition, low economic status and social exclusion are associated with a longer waiting time and preparation for surgery, which is further hampered by the high rate of cancellations and delays, making surgical time difficult [27-29].

This study has as positive points the analysis of a population with different degrees of vulnerability, given the socioeconomic disparities found in Brazil for centuries. This allows a more effective comparison between groups avoiding bias. On the other hand, it has as a negative side a transversal approach, which limits the study because it is not possible to create relations of causality between the variables.

\section{Conclusion}

It was concluded that there was a correlation between the various social indexes (HDI, IVS and Gini index) and the incidence and mortality due to Central Nervous System neoplasms in the pediatric population. This 
correlation is dependent on the age group, being in some cases positive and, in others, negative. Regarding mortality, there was a positive correlation between total mortality and IVS in the Midwest for the male population.

Therefore, it is extremely important that more research is done on the subject, since it is a public health concern. Allied to this, a better understanding of how social variables affect the incidence and mortality of pediatric neoplasias should be treated as a priority, since it is a population still in formation that can acquire sequels, impairing their quality of life for years and having their workforce diminished.

\section{References:}

1. OSTROM, Quinn T. et al. CBTRUS statistical report: primary brain and central nervous system tumors diagnosed in the United States in 2007-2011. Neuro-oncology, v. 16, n. suppl_4, p. iv1-iv63, 2014.

2. MORA, J.; PEREZ-JAUME, S.; CRUZ, O. Treatment of childhood astrocytomas with irinotecan and cisplatin. Clinical and Translational Oncology, v. 20, n. 4, p. 500-507, 2018.

3. STURM, Dominik; PFISTER, Stefan M.; JONES, David TW. Pediatric gliomas: current concepts on diagnosis, biology, and clinical management. Journal of Clinical Oncology, v. 35, n. 21, p. 2370-2377, 2017.

4. LOUIS, David N. et al. The 2007 WHO classification of tumours of the central nervous system. Acta neuropathologica, v. 114, n. 2, p. 97109, 2007.

5. ZELTZER, Lonnie K. et al. Psychological status in childhood cancer survivors: a report from the Childhood Cancer Survivor Study. Journal of Clinical Oncology, v. 27, n. 14, p. 2396, 2009.

6. MICHEL, Gisela et al. Psychological distress in adult survivors of childhood cancer: the Swiss Childhood Cancer Survivor study. Journal of Clinical Oncology, v. 28, n. 10, p. 1740-1748, 2010.

7. STRAUSER, David R. et al. Development of the perceived barriers scale: a new instrument identifying barriers to career development and employment for young adult survivors of pediatric CNS tumors. Journal of Cancer Survivorship, p. 1-9, 2018.

8. KIRCHOFF, A. C. et al. Physical, mental and neurocognitive status and employment outcomes in the childhood cancer survivor study cohort. Cancer Epidemiol Biomarkers Prev, v. 20, n. 9, p. 1838-49, 2011.

9. KIRCHHOFF, Anne C. et al. Unemployment among adult survivors of childhood cancer: a report from the childhood cancer survivors study. Medical care, v. 48, n. 11, p. 1015, 2010. 
10. STARFIELD, Barbara et al. Social class gradients in health during adolescence. Journal of Epidemiology \& Community Health, v. 56, n. 5, p. 354-361, 2002.

11. SOMMER, Isolde et al. Socioeconomic inequalities in noncommunicable diseases and their risk factors: an overview of systematic reviews. BMC public health, v. 15, n. 1, p. 914, 2015.

12. KEHM, Rebecca D. et al. Socioeconomic status and childhood cancer incidence: a population-based multilevel analysis. American journal of epidemiology, v. 187, n. 5, p. 982-991, 2017.

13. PAN, I.-Jen; DANIELS, Julie L.; ZHU, Kangmin. Poverty and childhood cancer incidence in the United States. Cancer Causes \& Control, v. 21, n. 7, p. 1139-1145, 2010.

14. KAMIHARA, Junne et al. Socioeconomic status and global variations in the incidence of neuroblastoma: call for support of population-based cancer registries in low-middle-income countries. Pediatric blood \& cancer, v. 64, n. 2, p. 321-323, 2017.

15. ALSTON, Robert D. et al. Cancer incidence patterns by region and socioeconomic deprivation in teenagers and young adults in England. British journal of cancer, v. 96, n. 11, p. 1760, 2007.

16. KEEGAN, Thomas J. et al. Case-control study of paternal occupation and social class with risk of childhood central nervous system tumours in Great Britain, 1962-2006. British journal of cancer, v. 108, n. 9, p. 1907, 2013.

17. BAQUET, Claudia R. et al. Socioeconomic factors and cancer incidence among blacks and whites. JNCI: Journal of the National Cancer Institute, v. 83, n. 8, p. 551-557, 1991.

18. RIBEIRO, Vera Masagão; VÓVIO, Claudia Lemos; MOURA, Mayra Patrícia. Letramento no Brasil: alguns resultados do indicador nacional de alfabetismo funcional. Educação \& Sociedade, v. 23, n. 81, 2002.

19. SANTOS, Nelson Rodrigues dos. SUS, política pública de Estado: seu desenvolvimento instituído e instituinte e a busca de saídas. Ciência \& saúde coletiva, v. 18, p. 273-280, 2013.

20. PULSIFER, Margaret B. et al. Cognitive and Adaptive Outcomes After Proton Radiation for Pediatric Patients With Brain Tumors. International Journal of Radiation Oncology* Biology* Physics, v. 102, n. 2, p. 391-398, 2018.

21. BUNIN, Greta R. et al. Relation between maternal diet and subsequent primitive neuroectodermal brain tumors in young children. New England Journal of Medicine, v. 329, n. 8, p. 536-541, 1993.

22. RAMIS, Rebeca et al. Risk factors for central nervous system tumors in children: new findings from a case-control study. PloS one, v. 12, n. 2, p. e0171881, 2017. 
23. Danysh HE, Mitchell LE, Zhang K, Scheurer ME, Lupo PJ. Trafficrelated air pollution and the incidence of childhood central nervous system tumors: Texas, 2001-2009. Pediatr Blood Cancer. 2015;62: 1572-1578. 10.1002/pbc.25549

24. Pollán M, López-Abente G, Aragonés N, Ruiz M. Malignant brain tumour mortality among children and adolescents: geographical distribution in Spain. J Neurol Sci. 1999;163: 127-136.

25. Infante-Rivard C, Weichenthal S. Pesticides and Childhood Cancer: An Update of Zahm and Ward's 1998 Review. Journal of Toxicology and Environmental Health, Part B. 2007;10: 81-99

26. AUSTIN, Mary T. et al. Health disparities and impact on outcomes in children with primary central nervous system solid tumors. Journal of Neurosurgery: Pediatrics, v. 18, n. 5, p. 585-593, 2016.

27. Birkmeyer NJO, Gu N, Baser O, Morris AM, Birkmeyer JD: Socioeconomic status and surgical mortality in the elderly. Med Care 46:893-899, 2008

28. . Linabery AM, Ross JA: Childhood and adolescent cancer survival in the US by race and ethnicity for the diagnostic period 1975-1999. Cancer 113:2575-2596, 2008

29. Trinh VT, Davies JM, Berger MS: Surgery for primary supratentorial brain tumors in the United States, 2000-2009: effect of provider and hospital caseload on complication rates. J Neurosurg 122:280-296, 2015

30. AHMAD, O. B. et al. GPE Discussion Paper Series: N.31 (ed World Health Organization) 1-14 (2001).

31. ATLAS DA VULNERABILIDADE SOCIAL NAS REGIÕES METROPOLITANAS BRASILEIRAS / Editores: Marco Aurélio Costa, Bárbara Oliveira Marguti. - Brasília: IPEA, 2015. 240 p.

32. BRASIL A. Programa das Nações Unidas para o Desenvolvimento; Instituto de Pesquisa Econômica Aplicada; Fundação João Pinheiro. Atlas do Desenvolvimento Humano no Brasil 2013.

33. MINISTÉRIO DA SAÚDE. DATASUS. Informações de Saúde. Indicadores de Dados Básicos - IDB 2012. 2019. Available: <http://www2.datasus.gov.br/DATASUS/index.php?area=0206>. 